Article

\title{
What Really Makes Secondary School Students "Want" to Study Physics?
}

\author{
Yannis Hadzigeorgiou ${ }^{1,2, *}$ (1) and Roland M. Schulz ${ }^{1}$ \\ 1 Imaginative Education Research Group, Department of Education, Simon Fraser University, Burnaby, \\ BC V5A 1S6, Canada; rmschulz@shaw.ca \\ 2 School of Education, University of the Aegean, Lesbos 811 00, Greece \\ * Correspondence: hadzigeo@rhodes.aegean.gr
}

Received: 16 October 2017; Accepted: 13 November 2017; Published: 21 November 2017

\begin{abstract}
This paper reports on a mixed-methods study with high school students. The study focused on the reasons they give with regard to "what they find interesting about their physics lesson" and "what makes them want to study their physics lesson" during a school year. The sample consisted of 219 students, who attended public high schools, located in various geographical regions of Greece. Journal entries made by all students - that is, students from junior high and senior high schools-were content-analyzed through a grounded theory approach. A total of eight categories were identified. Quantitative differences between these categories, and between the two groups of students, were also identified. Even though some of the identified categories are well-known motivators in science education, three specific categories deserve particular attention: "connection to one's own self", "purpose", and "utility". Notwithstanding the limitations of the present research design (i.e., volunteer sample, lack of standardization in students" and especially in teachers' activities), these categories, along with two quantitative indicators-that is, number of journal entries and student percentages - challenge us to rethink what makes the ideas of science, especially those of physics, meaningful or simply relevant to the life of the students.
\end{abstract}

Keywords: physics; science; motivation; engagement; learning; relevance; interest; self; teaching strategies; secondary education

\section{Introduction}

This paper, even though it reports on an exploratory study with secondary school students, provides some new insights into the complex problem of how to engage students in science. More specifically, these insights into the reasons students give for their interest in science and their motivation to study it, challenge us to rethink what we believe makes school science a really interesting and motivating school subject.

According to the literature, student engagement in science is quite problematic [1-3]. In addition, as the complexity of the field of science education shows [4], engaging all students in science can be a real challenge too. Nowadays, such challenge can be seen in STEM education $[5,6]$. Notwithstanding the importance of the Science for All proposal [7,8], which, we should acknowledge, is based on a democratic educational ideal $[9,10]$, it is important to bear in mind that one of the goals of school science education is to attract the next generation of scientists and engineers. Therefore the study of physical science, particularly physics, should be encouraged during the years of mandatory education. The question though is how to do this. This is a crucial question given that physics is not a popular subject. Students appear to prefer biology and environmental education to physical science [11-13]. 
On the other hand, there is evidence that, while students do acknowledge the importance of science, they do not really want to study it [14]. In addition, however, physics is a subject that has the potential to inspire students, boys and girls alike [15]. The present study is an attempt to identify the reasons for which secondary school students feel motivated to study physics. Notwithstanding the limitations of the present research design (see the results and discussion section), such information can be quite useful when it comes to designing curriculum and instruction, if our goal is to increase students' opportunities and possibilities for significant learning, even though generalizations, due to the limitations of the present study, cannot be made (see the results and discussion section).

\section{Rationale for the Study}

Given the unpopularity of physics, the problem of attracting students to physics remains quite pressing. One popular answer to the question regarding how to attract students to physics is by making physics relevant to the lives of students and also by making physics interesting. Indeed over the past two or so decades there have been proposals which aimed at making science education both personally and socially relevant to the lives of students [16,17].

However, what is a relevant or interesting physics curriculum? This second question, regardless of whether the latter refers to the explicit or even the taught curriculum, is not easy to answer. The reason is that there are conceptual problems inherent in the notions of both relevancy and interest, which (problems) make these two notions questionable in the context of "science education for all" [18]. In addition, due to these conceptual problems, questionnaires and interview scripts should be very carefully designed so that there is conceptual clarity in questions and also in statements with which students are supposed to agree or disagree. It is quite interesting to note that, according to a review study, the notion of "relevance", that is, a key term related to reform proposals in science education, is unclear and ambiguous [19].

In addition, it must be admitted that the problem of motivation is a complex one. Indeed, motivation, defined as "the process whereby goal-directed activity is instigated and sustained" [20] (p. 21), involves many factors, such as personal interests, instructional content that is personally and socially relevant and meaningful, psychological state, expectations, values and beliefs about education in general and learning in particular. Thus, a very careful research design is imperative, if one plans to study students' motivation. Even if one were to focus on one of those factors, because such factor is considered important in the process of motivation, there are still problems to be dealt with.

To illustrate these problems, one can look at the notion of personal interest, that is, a crucially important factor in the learning process [21]. First and foremost, a student may find science in general, or a science topic in particular, interesting, and still not want to study it. Second, a student's interest may be situational and thus may not last, something that poses problems with regard to sustained motivation necessary for purposeful learning [22,23]. In addition, third, a student may very well be interested in science without liking it. Indeed, it is very likely that a student who simply says during an interview (or answers a questionnaire question) that he or she finds the science class, a particular science topic, or even science as a school subject interesting does not necessarily feel motivated to study science [24].

On the other hand, if we take into account the fact that the most effective factor contributing to students' decision to study science is their interest in the various science topics, and that students are interested in science if they are already familiar with these topics [25], one can understand the challenge that science teachers really face: familiarizing students with science content knowledge presupposes an initial degree of interest in science. The circularity of the argument is quite apparent.

It is for these reasons that students' own views of what really motivates them to study physics are imperative. In fact, we believe that such views are crucial and should be known before any attempts to design curriculum and teaching sequences are made. The study reported in this paper is an attempt to give students the opportunity, on the one hand, to reflect on what makes them want to study physics, 
and, on the other hand, to take as much time as they want in order to write about the things they think make them want to study physics.

\section{Context and Methods}

With the aforementioned rationale in mind we attempted to give students voice based on their school physics class experiences. To this end we decided to use a mixed-methods design involving both a qualitative and a quantitative analysis of journal entries and not questionnaires or interviews. The reason for this is that while questionnaires may be completed by students because they are asked to, or because they have to-and there is also the problem of going into some depth-interviews could place a young student "on the spot", without giving him/her enough time for reflection.

So we tried to make up for those two shortcomings by utilizing students' journal entries, as a means of data collection. This was also thought to be more appropriate to our study given that many teaching-learning events take place during a school year, thus providing material for reflection on the part of students. Apparently, an interview, especially with students, no matter how long, imposes certain limitations on such kind of reflection on multiple events. Moreover, reflection needs time, as was said above, something that is not possible through the use of an interview, which must satisfy certain time restrictions (i.e., because of practical reasons and other constraints, interviews last between one and two hours).

The journals were to be used over a period of a whole school year (Mid October-end of April/early May). These were to be anonymous, and the students would write whenever they felt like writing and reflecting, preferably though after each individual lesson (for the reason that they would remember what transpired during the teaching process). The students were not given any guidance or reminders with regard to how to make journal entries, except that their comments would be on three things: (a) whether they found something interesting about their physics lesson; (b) whether and why they really wanted to study their physics lesson at home (following their teacher's introduction in the classroom), and (c) whether and why they really wanted to learn more about what they were taught in their physics class, that is, about anything relating to their physics lesson, but which goes beyond class requirements and assignments. The teachers who taught these students made sure, by providing specific examples, that the latter understood the difference between finding something interesting about their physics lesson and feeling motivated to study this lesson.

With regard to standardization, the only guidance that was given to the teachers was that they would use their main teaching strategies (e.g., storytelling, inquiry science, art and science connections, argumentation, wonder cognitive conflict, argumentation) the same number of times. Thus, it was agreed upon, through email communication with a sample of teachers, that that number would be five. No guidance to relate these strategies with specific science content was made.

The sample was a convenient sample, in the sense that the participants were all volunteers. The 219 students ( 140 from junior high schools and 79 from senior high schools attended 46 public high schools, located in various geographical regions of Greece, and were contacted by their teachers after the end of class at the beginning of October. The teachers asked all of the students in each classroom, whether they wanted to participate in a study, explaining to them what the study would involve. The only criterion for their selection was the willingness on their part to participate in this project. It was made explicit to them that they would receive no credit for their participation. Such a sample, however, was quite useful for the purpose of the present research because it included students from various backgrounds and a considerable large number of teachers, who were told to teach using a variety of teaching strategies.

The analysis of students' journals was based on a grounded theory approach [26,27], in which the content of the journals was scrutinized reflexively and iteratively for major emerging categories. This meant that the data analysis was mainly an inductive process (i.e., the initial coding of the data was not based upon a preexisting theoretical framework). However, a deductive analysis was also used in the later phases of the analysis, after the categories had emerged and been finalized. What should 
be noted though is that the data analysis was a recursive process, in the sense that there was always a moving back and forth, as needed, throughout the whole process. The unit of our analysis was the paragraph. In addition, the reliability of this analysis was achieved with the use of two external researchers who checked both the codes and the coding process. Both external researchers check all the material, and all codes. Given the nature of the design and the possibility of an overlap between the codes they had to agree on all codes.

The final categories, as described below, can show their core as well their borders (e.g., between "teaching strategies" and "demonstrations", "relevance to everyday life" and "connection to the self').

- Relevance to everyday life: Students' awareness of a relationship of any aspect of physics (e.g., content, science process skills, applications) with human life (in general);

- Connection to the self: Students' awareness that an aspect of physics is related in some way to their own self, their own life;

- Teaching strategy: The way the subject matter was presented to the students.

- Demonstrations: Experimental and hand-on activities carried out by the teacher at any point of the teaching process;

- Utility: Students' awareness that they can do something in their daily life with their knowledge of physics (e.g., concepts, process skills);

- Purpose: Having or searching for a reason to study something that relates to physics;

- Social significance: Students' awareness that physics has helped shape our society to its present advanced state;

- Scientists' life experiences: Students' awareness of the conditions in which scientists lived and worked as well as what they went through in order to contribute to the development of scientific knowledge.

\section{Results and Discussion}

The results of the present study do not support any generalizations given the fact that the sample consisted of volunteers. Indeed, it may very well be the case that such a sample is correlated with the research findings. Moreover, the lack of standardization, with regard to teacher and student activities (due to the way the sample was drawn and the difficulty to standardize teachers' activities), made the interpretation of the results problematic, even though care was taken to deal with this specific problem in the coding process. In our view an important limitation of this study is lack of information about how each specific strategy was implemented. Nevertheless, the analysis of students' journal entries did yield a number of categories, depending upon the context of this analysis (see Tables 1-3), which means that students are motivated by a number of factors, and these need to be considered by science teachers and science educators alike. These categories can also provide food for thought for those who will design research designs in this area in the future.

What should also be mentioned is that "relevance to everyday life", "utility" and "connection to the self" were coded as separate final categories, on the basis of the meaning that students gave to them. For example, the paragraph "I want to study physics when I see that is useful in my life [...] the electricity chapter we did yesterday made me want to study because electricity is something that is part of my own life [...] not just electric current and light bulbs", rendered two final categories, namely, "utility" and "connection to the self". By the same token, the paragraph, "Yesterday, when we were told about the applications of levers in our daily life, I realized that we use them all in our life [...] so I tried to read more stuff on levers and see how my own life can be made easier" rendered two categories, namely "relevance to everyday life" and "utility".

It is likely that a category may have been counted more than once, due to the overlapping of the meaning of the categories "relevance to everyday life", "utility", and "connection to the self". However, such likelihood is small given the final coding of the categories (see previous section). On the other hand, a category may have not been counted at all. For example, in the aforementioned example 
about levers, a third category, namely, that of "connection to the self" could be added, as the pupil, who made this specific entry, in addition to seeing the relevance of levers to life, tried to learn more about them, in order to make his/her own life easier.

However, despite these shortcomings of the present analysis, what counts is the emerged categories, form a qualitative perspective, and some differences between the groups form a quantitative point of view. The most important findings can be summarized as follows:

- What a student finds interesting does not necessarily make him/her to want to study his/her physics lesson, let alone to study it further, that is, to study it because he/she wants to know more than what is required by the school curriculum. This is, perhaps, the most important message that this study can send to the science education community;

- While "utility", "relevance to everyday life" and "teaching strategies" were the most cited reasons for making junior high school students want to study their lesson and also want to study it further, for senior high school it was "connection to the self" and "utility" the most cited reasons;

- Flashy demonstrations that make science fun and are found by students to be very interesting are not always a reason for making them to want to study science, at least physics;

- The percentage of students (from both groups) who made entries decreased significantly from what students found interesting about their physics lesson to what really made them want to study their lesson, and then to what made them to devote time to learn more about their physics lesson beyond class requirements.

However, there are some other findings that also deserve attention. First, identical reasons for finding the physics lesson interesting and wanting to study it at home were found for both groups of high school students, that is, lower grades and higher grades, but with considerable variation in the frequencies regarding journal entries and the percentage of students who made those entries (see Tables 1-3). For example, while for junior high school students "demos" were found to be the most frequent factor that made the lesson interesting (100\% of students made 467 entries), for senior high school students it was the "connection to the self" that was found to be the most important reason for finding the lesson interesting ( $70 \%$ of students made 256 entries). Also one can see in Table 1 that a higher percentage of students from the junior high school group made many more entries compared to the senior high school group with regard to "relevance to everyday life" and "teaching strategy". Such a difference is interesting and could be interpreted by reference to the fact that for the senior high school group the "connection to the self" was the category with the highest number of journal entries (256) and the highest percentage of students who made those entries (83.5). For the older group of students this latter category must have "overshadowed" the other two, that is, relevance to everyday life and teaching strategies, something that is also supported by the data in Table 2.

Table 1. Emerged categories referring to "What the students found interesting about their physics lesson" with the number of journal entries and the percentage of students who made those entries for both groups.

\begin{tabular}{lcc}
\hline \multirow{2}{*}{ Categories } & \multicolumn{2}{c}{ Frequency/Student Percentage } \\
\cline { 2 - 3 } & Junior High School & Senior High School \\
\hline 1. Demonstrations & $467 / 100$ & $230 / 70.8$ \\
2. Relevance to everyday life & $381 / 85.7$ & $115 / 75.9$ \\
3. Teaching Strategy & $358 / 92.8$ & $212 / 73.4$ \\
4. Connection to the self & $112 / 45.7$ & $256 / 83.5$ \\
5. Utility & $180 / 70$ & $161 / 72.1$ \\
6. Social Significance & - & $24 / 8.8$ \\
\hline
\end{tabular}


Table 2. Emerged categories referring to "What really made students want to study their physics lesson" with the number of journal entries and the number of students for both groups.

\begin{tabular}{lcc}
\hline \multirow{2}{*}{ Categories } & \multicolumn{2}{c}{ Frequency/Student Percentage } \\
\cline { 2 - 3 } & Junior High School & Senior High School \\
\hline 1. Demonstrations & $111 / 30$ & $38 / 15.1$ \\
2. Relevance to everyday life & $250 / 57.1$ & $85 / 39.2$ \\
3. Teaching Strategy & $192 / 67.8$ & $98 / 37.9$ \\
4. Connection to the self & $83 / 22.8$ & $209 / 73.4$ \\
5. Utility & $154 / 61.4$ & $146 / 60.7$ \\
6. Purpose of learning & $24 / 2.8$ & $66 / 39.2$ \\
7. Scientists' life experiences & $18 / 4.2$ & $22 / 7.5$ \\
8. Social Significance & - & $24 / 8.8$ \\
\hline
\end{tabular}

Table 3. Emerged categories with the number of journal entries and the number of students for both groups regarding "What really made students want to study further beyond class requirements".

\begin{tabular}{lcc}
\hline \multirow{2}{*}{ Categories } & \multicolumn{2}{c}{ Frequency/Student Percentage } \\
\cline { 2 - 3 } & Junior High School & Senior High School \\
\hline 1. Demonstrations & $34 / 9.2$ & - \\
2. Relevance to everyday life & $101 / 22.8$ & $38 / 26.5$ \\
3. Teaching Strategy & $88 / 29$. & $45 / 27.8$ \\
4. Connection to the self & $42 / 9.2$ & $161 / 62$ \\
5. Utility & $121 / 45$ & $115 / 48.1$ \\
6. Purpose of learning & $10 / 2.1$ & $50 / 36.7$ \\
7. Scientists' life experiences & $8 / 2.1$ & $17 / 6.3$ \\
8. Social Significance & - & $22 / 7.5$ \\
\hline
\end{tabular}

Second, contributing motivational factors for more than 50\% of students from the junior high school group were found to be "relevance to life", "teaching strategy", and "utility", while for the pupils from the senior high school group it was "utility" and "connection to the self". In addition, it is quite interesting to note that these two factors were also found important by more than $50 \%$ of the students from the senior high group when it came to their decision to study their lesson further, beyond class requirements and assignments. With regard to the junior high school group, it was only "utility" that was thought a contributing factor by more than $40 \%$ of pupils when it came the same decision.

Third, while the analysis of students" journal entries rendered five categories for the junior high school group and six categories for the senior high group, in the case in which students wrote about what they found interesting about their physics lesson, the analysis, in the case in which students wrote about what really made them want to study their lesson, rendered eight categories. For example, "purpose" and "the scientists" life experiences" were found by some students to be important reasons for making them want to study.

Fourth, "social significance" was found an important reason for some students from the older group, but no student from the younger group made any reference to this factor.

Fifth, the idea of "utility" is considered important by both student groups, while "connection to the self" is an important reason for wanting to study and even want to study further. This latter finding is in line with previous research findings, namely, that personal identity is an important factor to be considered in the context of learning school science [17].

Sixth, "purpose of learning" and "the scientists' life experiences" were reported factors that contributed to pupils' motivation to study and study further. However, there was more than $30 \%$ difference between the two groups. Why purpose was considered by more than one third of the senior high school group an important contributing factor and only by less than $3 \%$ of the junior high group could be attributed to the possibility that older pupils were in search of meaning compared 
to younger ones. It may also have been that the idea of purpose was not externalized by the younger pupils. On the other hand, the fact that the inclusion of socio-scientific issues must have played a role in making the older students find a purpose in physics should also be considered.

Seventh, even though demonstrations were found by all pupils to be something interesting, only $30 \%$ from the junior high school group and 15\% from the senior high school group thought that demonstrations was a factor that motivated them to study. These two percentages dropped to $9 \%$ and $0 \%$ respectively, when it came to pupils' motivation to study further, beyond class requirements and assignments.

Eight, with regard to the teaching strategies, "cognitive conflict" and "inquiry science" were identified as the strongest motivators among all students, with cognitive conflict to be the most important reason for making one want to learn physics. Indeed cognitive conflict was identified as a category with the highest frequency and the highest number of students. Such finding is in line with previous research findings [17].

It is interesting to point out that storytelling, integrating art and science, and dramatization were not considered by several students as something that would make them want to study their physics lesson, even though they did find these strategies interesting. One reason may very well be how these strategies were implemented, something that cannot be assessed in the context of the present study - and this is one of its limitations-while another reason may be that teaching strategies are not considered as important as utility and connection to the self. What, however, needs to be pointed out is that, while $92 \%$ and $73 \%$ of the students from the junior high school group and the senior high school group respectively found the strategy interesting (and very interesting), these percentages dropped to $67 \%$ and $37 \%$ respectively when it came to students' motivation to study physics (see Table 4).

Table 4. Percentage of students (junior high/senior high) who made journal entries and the reasons (emerged categories) for which (a) they found their physics lesson interesting, (b) they wanted to study it, and (c) they wanted to study beyond class requirements.

\begin{tabular}{lccc}
\hline \multicolumn{1}{c}{ Emerged Categories } & “Find Interesting" & “Want to Study" & “Want to Study Further" \\
\hline 1. Demonstrations & $100 / 70.8$ & $30 / 15.1$ & $9.2 / 0$ \\
2. Relevance to life & $85.7 / 75.9$ & $57.1 / 39.2$ & $22.8 / 26.5$ \\
3. Teaching Strategy & $92.8 / 73.4$ & $67.8 / 37.9$ & $29.2 / 27.8$ \\
4. Connection to the self & $45.7 / 83.5$ & $22.8 / 73.4$ & $9.2 / 62$ \\
5. Utility & $70 / 72.1$ & $61.4 / 60.7$ & $45 / 68.1$ \\
6. Purpose of learning & & $2.8 / 39.2$ & $2.1 / 36.7$ \\
7. Scientists' life experiences & & $4.2 / 7.5$ & $2.1 / 6.3$ \\
8. Social Significance & $0 / 8.8$ & $0 / 8.8$ & $0 / 7.5$ \\
\hline
\end{tabular}

It deserves to be noted that, even though the category "purpose of learning" was found to be an important reason for making students from the older group to want to study physics (39\%)—as these students made an explicit reference to "why they want to study physics"—purpose must have been an implicit reason for many students. It may very well be the case that "relevance of subject matter to everyday life", "practical utility" and "connection of physics content to the self" motivated some students to study physics and even study it further beyond class requirements, without though making this explicit in their journal entries.

What, therefore, must be pointed out here is that the list of the questions that are commonly and explicitly asked by science educators [28] needs to be complemented by a question of purpose. Notwithstanding the importance of such questions as "What do we know?" (the ontological question), "How do we know?" (the procedural question), "What can do we with what we know?" (the technological question), and "How can we communicate what we know?" (the communicative question), a question of purpose, namely, "Why should we know?" should also be kept in mind when planning curriculum and instruction, despite the difficulty to answer such question [29]. As Woolnough commented, the problem is not that the theories of learning get the answers wrong, but that they ask 
the wrong questions in the first place. According to him, instead of asking "how do students learn?", we should ask "what makes students want to learn?" [30].

What should also be pointed out is that the notion of relevance, although an important one in curriculum planning and instruction, for many senior high school students, it was the idea of the connection of self that played a role in their decision to study physics, and even to study it further, that is, beyond class requirements. As can be seen in Table 4, the percentages of senior high school students were 73 and 62 respectively. Why the percentage of junior high school students, with regard to the category "connection to the self", was not as high as that of senior high school students, could be explained by reference to the fact that a higher percentage of older students are in search of an existential meaning, compared with their younger counterparts. Certainly, in-depth interviews with some of the junior high school students could shed more light on this difference between the two student groups, but that was not part of the present study.

Nevertheless, the emerged categories (see Tables 5 and 6), along with the quantitative data, especially the student percentages, provide food for thought for both science educators and science teachers, especially those who teach physics in secondary education. The implications of the above findings for school science education, especially with regard to curriculum planning and the design of teaching sequences, are the following: First, engagement in science is a complex process, which is influenced by a number of factors, some of which are quite personal and hence unpredictable. These factors should certainly complement the factors that enhance intrinsic motivation, and which are recommended by the literature (e.g., curiosity, control, challenge and fantasy) [20]. In addition, second, the categories of "purpose" and "self" point to the crucial role that phenomenological approaches can play in the teaching and learning of physics, and perhaps science in general. Intentionality that may very well be absent from constructivist methodologies, but, according to this study, intentionality is crucial, at least, for the older students.

Table 5. Emerged categories and students' most cited reasons for "What made them want to study physics".

\begin{tabular}{|c|c|}
\hline First Order Categories & Second Order Categories \\
\hline Relevance to everyday life & $\begin{array}{l}\text { "making a difference to people's life" } \\
\text { "helping one cope with daily life" } \\
\text { "seeing the relation of physics to everyday life" } \\
\text { "seeing that physics is not just theory, but everyday practice" } \\
\text { "helping one apply physics in everyday life" } \\
\text { "seeing the relationship between physics and technology" }\end{array}$ \\
\hline Teaching Strategy & $\begin{array}{l}\text { "storytelling" } \\
\text { "dramatization/role-play" } \\
\text { "inquiry" } \\
\text { "science through art" } \\
\text { "cognitive conflict/wonder" } \\
\text { "argumentation" }\end{array}$ \\
\hline Connection to the self & $\begin{array}{l}\text { "helping one with career choices" } \\
\text { "being part of one's self/identity" } \\
\text { "helping one become better" } \\
\text { "seeing a relationship with one's own self" }\end{array}$ \\
\hline Utility & $\begin{array}{l}\text { "realizing that physics can be really useful" } \\
\text { "seeing how one can use physics ideas in one's everyday life" } \\
\text { "seeing usefulness even in the abstract ideas of physics" }\end{array}$ \\
\hline Purpose & $\begin{array}{l}\text { "knowing why should one study physics" } \\
\text { "knowing why should one invest time even if one does not have an interest in physics" } \\
\text { "knowing why a science idea is valuable" }\end{array}$ \\
\hline Social Significance & $\begin{array}{l}\text { "very important for our society" } \\
\text { "without the applications of physics we would live like primitive people" }\end{array}$ \\
\hline Scientists' life experiences & $\begin{array}{l}\text { "knowing that great scientists faced problems like all people" } \\
\text { "seeing my own self in these scientists' experiences" }\end{array}$ \\
\hline
\end{tabular}


Table 6. Types of strategies referring to "what made students want to study physics" with the number of journal entries and the percentage of students who made those entries for both groups.

\begin{tabular}{lcc}
\hline \multirow{2}{*}{ Strategies } & \multicolumn{2}{c}{ Number of Journal Entries/Number of Students } \\
\cline { 2 - 3 } & Junior High School & Senior High School \\
\hline 1. Cognitive conflict & $72 / 39.2$ & $31 / 27.8$ \\
2. Inquiry & $50 / 22.8$ & $37 / 24$ \\
3. Narratives/storytelling & $35 / 12.8$ & $12 / 8$ \\
4. Art-science connections & $15 / 6.4$ & $6 / 5$ \\
5. Dramatization & $7 / 2.8$ & $2 / 1.4$ \\
6. Argumentation & $3 / 1.4$ & $10 / 4.2$ \\
\hline
\end{tabular}

\section{Summary and Conclusions}

This study investigated the reasons secondary school students give for what they find interesting about their physics lessons taught by their teacher, and also for what makes them want to study these lessons. Because of its limitations (i.e., volunteer sample, lack of standardization in students' and especially teachers' activities), this study cannot be used to influence science education policy - this would require more research and more structured designs-but its results can provide some useful insights into the science curriculum, and also into the design of teaching sequences. Even though some of the identified categories, such as "relevance to everyday life", "cognitive conflict", "teaching through storytelling", "art-science connections" are well-known motivators in science education $[17,20,25]$, four specific categories deserve particular attention: "connection to the self", "purpose", "utility", and "cognitive conflict". These categories, along with some quantitative indicators, such as number of journal entries and student percentages, challenge us to rethink what makes the ideas of science, especially those of physics, meaningful or simply relevant to the life of students. The importance of the categories "connection to the self" and "cognitive conflict" is supported by previous research [29,31-34].

With regard to teaching physics to students in the higher grades of secondary school, the idea of "relevance" seems to be complemented with the idea of the self. Indeed, evidence from this study suggests that, at least for the older secondary school students, the context of everyday life, which supposedly makes physics, and science in general, relevant to the life of the students, is not enough to motivate students to want to study physics, unless in this context students perceive a relationship with their own self. The explicit reference, at least on the part of the older secondary school students, to the idea of self-and not just to everyday life (which can be in many cases quite abstract)—needs to be seriously considered by science teachers and science educators. Osborne had argued that "Any consideration of the role of science education must begin not with an internalist view of its content and curricula, but rather with an externalist perception of the society it serves" [35] (p. 42, italics mine). The data from this study provide some evidence that "the perception of society" should be complemented with "the perception of the self". This is an important message for science teachers if they want to encourage involvement with school science. The analysis of students' journal entries did provide evidence that even the notion of utility was perceived in relation to students' own self, to their personal life, and not in relation to everyday life in general. Such findings also point to the crucial role that philosophy of education can play in science education [36]. Indeed, notwithstanding the importance of methodological sophistication, what matters in the end is conceptual clarity in our theoretical framework $[29,37]$.

And if emotions are crucially important in the context of teaching and learning school science [38-42], and the empirical evidence so far suggests that that engagement in science is an important parameter of the learning process $[2,3,43,44]$, then the categories identified by the present study should be seriously considered by the science education community. Certainly, further in-depth studies of the reasons students themselves give for their motivation to study physics, and science in general, need to be conducted, as these studies will help us better understand what makes students 
"want to learn". For as Margaret Bateson argued, what is important is not what one knows but what one is willing to learn [45].

Thus, the results of the present study have two important implications for future research. First, we need to pay attention to the research design - very few efforts have been made to go beyond the use of questionnaires [33] — so that we capture the complexity of the teaching-learning process. In addition, second, we need to deepen our understanding with regard to the decline of student interest in science (see Table 4).

Author Contributions: The study was designed by both authors, and the paper was written by both of them too. Yannis Hadzigeorgiou did the analysis of the data.

Conflicts of Interest: The authors declare no conflict of interest.

\section{References}

1. Hadzigeorgiou, Y.; Stivaktakis, S. Encouraging Involvement with School Science. J. Curric. Pedagog. 2008, 5, 138-162. [CrossRef]

2. Pugh, K.J. Transformative Experience: An Integrative Construct in the Spirit of Deweyan Pragmatism. Educ. Psychol. 2011, 46, 107-121. [CrossRef]

3. Pugh, K.; Bergstrom, C.; Spencer, C. Profiles of transformative engagement: Identification, description, and relation to learning and instruction. Sci. Educ. 2017, 101, 369-398. [CrossRef]

4. Matthews, M. Science Teaching: The Contribution of History and Philosophy of Science; Routledge: New York, NY, USA, 2015.

5. Ceci, S.; Ginther, D.; Kahn, S.; Williams, W. Women in academic science: A changing landscape. Psychol. Sci. 2014, 15, 75-141. [CrossRef] [PubMed]

6. Wang, M.; Eccles, J.; Kenny, S. Not lack of abilities but lack of choice: Individual and gender differences in choice of careers in science, technology, engineering, and mathematics. Psychol. Sci. 2013, 14, 1-6. [CrossRef] [PubMed]

7. American Association for the Advancement of Science (AAAS). Science for All Americans; Oxford University Press: Oxford, NY, USA, 1990.

8. National Research Council. Inquiry and the National Science Education Standards; National Academic Press: Washington, DC, USA, 2007.

9. Hadzigeorgiou, Y. Implications of R.S. Peters' Notion of Cognitive Perspective and Its Implications for Science Education. Educ. Philos. Theory 2017. [CrossRef]

10. Hadzigeorgiou, Y.; Konsolas, M. Global Problems and the Curriculum: Toward a Humanistic and Constructivist Science Education. Curric. Teach. 2001, 16, 39-49. [CrossRef]

11. Jenkins, E.W. Student opinion in England about science and technology. Res. Sci. Technol. Educ. 2006, 24, 59-68. [CrossRef]

12. Jenkins, E.; Pell, R. The Relevance of Science Education Project (ROSE) in England: A Summary of Findings; Centre for Studies in Science and Mathematics Education; University of Leeds: Leeds, UK, 2006.

13. Williams, C.; Stanisstreet, M.; Spall, K.; Boyes, E.; Dickson, D. Why aren't secondary students interested in physics? Phys. Educ. 2003, 38, 324-329. [CrossRef]

14. Jenkins, E.W.; Nelson, N.W. Important but not for me: Students' attitudes towards secondary school science in England. Res. Sci. Technol. Educ. 2005, 23, 41-57. [CrossRef]

15. Hadzigeorgiou, Y.; Garganourakis, V. Using Nikola Tesla's story and experiments, as presented in the film "The Prestige", to promote scientific inquiry. Interchange 2010, 41, 363-378. [CrossRef]

16. Aikenhead, G.S. Review of research on humanistic perspectives in science curricula. In Proceedings of the 2nd European Science Education Research Association (ESERA) 2003 Conference, Noordwijkehoot, The Netherlands, 19-23 August 2003.

17. Hadzigeorgiou, Y. Imaginative Science Education; Springer: Cham, Switzerland, 2016.

18. Hadzigeorgiou, Y. A critique of science education as socio-political action from the perspective of liberal education. Sci. \& Educ. 2015, 24, 259-280. [CrossRef]

19. Stuckey, M.; Hofstein, A.; Mamlok-Naaman, R.; Eilks, I. The meaning of "relevance" in science education and its implications for the science curriculum. Stud. Sci. Educ. 2013, 49, 1-34. [CrossRef] 
20. Pintrich, P.; Schunk, D. Motivation in Education: Theory, Research, and Applications; Prentice-Hall: Englewood Cliffs, NJ, USA, 1996.

21. Klassen, S.; Froese-Klassen, C. The role interest in learning science through stories. Interchange 2014, 45, 133-151. [CrossRef]

22. Hadzigeorgiou, Y. Some thoughts on the notion of purposeful learning. Educ. Forum 2001, 65, 316-326. [CrossRef]

23. Hart, C.; Mulhall, P.; Berry, A.; Loughran, J.; Gunstone, R. What is the purpose of this experiment? Or can students learn something from doing experiments? J. Res. Sci. Teach. 2000, 37, 655-675. [CrossRef]

24. Callan, E. Interests and the curriculum. In Philosophy of Education; Hare, W., Portelli, J., Eds.; Detselig Enterprises: Calgary, AB, Canada, 1988; pp. 77-86.

25. Mamlok-Naaman, R. How can we motivate high school students to study science? Sci. Educ. Int. 2010, $22,5-17$.

26. Charmaz, K. Constructing Grounded Theory; Sage: London, UK, 2006.

27. Strauss, A.; Corbin, J. Basics of Qualitative Research: Techniques and Procedures for Developing Grounded Theory; Sage: Thousand Oaks, CA, USA, 2008.

28. Osborne, J. Beyond constructivism. Sci. Educ. 1996, 80, 53-82. [CrossRef]

29. Hadzigeorgiou, Y. On Humanistic Science Education. ERIC DOCUMENT, ED506504; 2005. Available online: http:/ / files.eric.ed.gov/fulltext/ED506504.pdf (accessed on 15 October 2017).

30. Woolnough, B. Learning science is a messy process. Sci. Teach. Educ. 1998, 23, 17-18.

31. Abrams, E.; Middleton, M.; Benson, J. The development of motivation and academic identity for science learning in early adolescents from indigenous communities. In Proceedings of the National Association for Research in Science Teaching's Annual Conference, Anaheim, CA, USA, 17-21 April 2009.

32. Hunsik Kang, H.; Scharmann, L.; Kang, S.; Noh, T. Cognitive conflict and situational interest as factors influencing conceptual change. Int. J. Environ. Sci. Educ. 2010, 5, 383-405.

33. Gibson, H.L.; Chase, C. Longitudinal impact of an inquiry-based science program on middle school students' attitudes toward science. Sci. Educ. 2002, 86, 693-705. [CrossRef]

34. Potvin, P.; Hasni, A. Interest, motivation and attitude towards science and technology at K-12 levels: A systematic review of 12 years of educational research. Stud. Sci. Educ. 2014, 50, 85-129. [CrossRef]

35. Osborne, J. Making science matter. In A Vision for Science Education; Cross, R., Ed.; RoutledgeFalmer: London, UK; New York, NY, USA, 2003; pp. 36-52.

36. Schulz, R.M. Philosophy of education and science education: A vital but underdeveloped relationship. In International Handbook of Research in History, Philosophy and Science Teaching; Matthews, M., Ed.; Springer: Dordrecht, The Netherlands, 2014; pp. 1259-1316.

37. Withey, D. Education and the cult of relevance. In Philosophy of Education; Hare, W., Portelli, J., Eds.; Detselig Enterprises: Calgary, AB, Canada, 1988; pp. 87-99.

38. Zembylas, M. Emotions and science teaching: Present research and future agenda. In Beyond Cartesian Dualism: Encountering Affect in the Teaching and Learning of Science; Alsop, S., Ed.; Springer: Berlin, Germany, 2005; pp. 123-132.

39. Yager, R.E. A Vision for What Science Education Should Be Like for the First 25 Years of a New Millennium. Sch. Sci. Math. 2000, 100, 327-341. [CrossRef]

40. Hadzigeorgiou, Y. Relationships, Meaning and the Science Curriculum. Curric. Teach. 1997, 12, 83-89. [CrossRef]

41. Hadzigeorgiou, Y.; Schulz, R.M. Romanticism and Romantic Science: Their Contribution to Science Education. Sci. E Educ. 2014, 23, 1963-2006. [CrossRef]

42. Hadzigeorgiou, Y.; Klassen, S.; Klassen, C.F. Encouraging a “Romantic Understanding” of Science: The Effect of the Nikola Tesla Story. Sci. E Educ. 2011, 21, 1111-1138. [CrossRef]

43. Hadzigeorgiou, Y.P. Fostering a Sense of Wonder in the Science Classroom. Res. Sci. Educ. 2011, 42, 985-1005. [CrossRef]

44. Hadzigeorgiou, Y. Reclaiming the value of wonder in science education. In Wonder-Full Education: The Centrality of Wonder in Teaching and Learning Across the Curriculum; Egan, K., Cant, A., Judson, G., Eds.; Routledge: New York, NY, USA, 2014; pp. 40-66.

45. Bateson, M. Willing to Learn: Passages of Personal Discovery; Steerforth Press: New York, NY, USA, 2004.

(C) 2017 by the authors. Licensee MDPI, Basel, Switzerland. This article is an open access article distributed under the terms and conditions of the Creative Commons Attribution (CC BY) license (http://creativecommons.org/licenses/by/4.0/). 